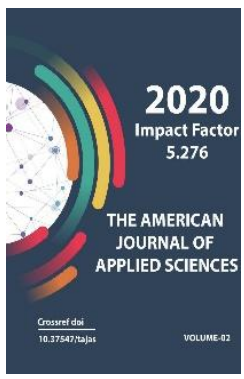

\title{
The Concept Of Pedagogical Skills, Its Role And Importance In Teaching
}

\author{
Aziza Aminovna Ikromova \\ Lecturer, ESP For Natural Sciences Department, Bukhara State University, Uzbekistan.
}

Journal Website:

http://usajournalshub.c

om/index,php/tajas

Copyright: Original content from this work may be used under the terms of the creative commons attributes 4.0 licence.

\section{ABSTRACT}

The article provides a comprehensive analysis of the fact that the success of the pedagogical activity depends in many ways on his or her personality, character, and interaction with students. But in general, their impact on the educational process seems insignificant. However, an experienced educator will focus on how his or her behavior has affected students, making the necessary adjustments and improvements. The inspiring challenge of such teachers is to instill in students a sense of confidence that their desire to learn will enable them to do better. In this case, the methods of teaching and upbringing become a means of realizing the qualities embodied in the personality of the teacher and the transfer of moral qualities from him to the student.

\section{KEYWORDS}

Pedagogical activity, educational process, pedagogue, methods of education and upbringing, moral qualities, intellectual potential.

\section{INTRODUCTION}

Every Resolution of the Cabinet of Ministers of the Republic of Uzbekistan and the President of the Republic of Uzbekistan pays special attention to the education of a harmoniously developed generation and the improvement of their professional skills, first of all, in educational institutions. In particular, the announcement of 2010 as the Year of Harmoniously Developed Generation has placed great responsibilities on educators and 
educators[1]. In particular, the Resolution of the First President of the Republic of Uzbekistan I.A.Karimov on the State Program "Year of harmoniously developed generation" states: Implementation of a wide range of well-targeted measures to create the necessary conditions and opportunities for the development of responsible and wellrounded individuals has been identified as an important task. Today, first of all, it is necessary to create a solid foundation for the continuous improvement of the level and knowledge of future teachers. In-depth study of the subject "Pedagogical skills" is important in finding solutions to these problems in higher pedagogical education[2].

\section{MATERIALS AND METHODS}

Scientists of the Ural State Professional Pedagogical University (BezrUkova V.S., Romantsev G.M., Tkachenko E.V., Zeer E.F.)[3] made a worthy contribution to the development of the theory of pedagogical skills of engineers and teachers. Juraev R.H., Nishonaliev U.N., Mirsaidov K.J., Choriev E.T. are among the pedagogical scientists on this issue in Uzbekistan and others have conducted effective research[4].

Pedagogical skills as a whole system consists of the following components: the pedagogical personality of the teacher, his interests, values and ideals are aimed at raising a harmoniously developed generation; have professional knowledge of specialty subjects, teaching methods, pedagogy and psychology; pedagogical skills (communication skills, diligence, foresight, professional independence, rapid comprehension of sensory information ("reading from the face"); mastery of pedagogical techniques, i.e. self-management, interaction and collaboration.

\section{RESULT AND DISCUSSION}

What is pedagogical skill? What is its essence? What do you need to know to own them? Modern pedagogy and psychology have different interpretations of the concept of "pedagogical skill". In particular, the definition in the "Pedagogical encyclopedia" is as follows: Based on the essence of this definition, the content of the concept of pedagogical skills of a teacher can be interpreted as follows:

1. A high level of culture is a high indicator of knowledge and intelligence.

2. He has a perfect knowledge of his subject. Thorough knowledge of sciences such as pedagogy and psychology, the ability to use them in their professional activities. Excellent knowledge of the methods of educational work[5].

The system of pedagogical skills consists of the following interrelated key components:

- Obedience to the requirements of pedagogical humanity.

- Excellent knowledge of the profession in connection with other disciplines.

- Pedagogical skills.

- Thorough mastery of the secrets of pedagogical techniques[6].

Among all professions.

The teaching profession has a unique and important social significance. After all, a teacher is an architect of the perfection of the heart of the younger generation, a person who educates young people. Today, he ideologically and politically hardens young people, teaches them the laws of nature, society, social life, the development of thinking, prepares young people for work, helps them to master the secrets of the profession, and society. 
- solves socio-economic situations that are important for That is the responsibility;

- a profession in which the teacher seeks ways to become a master of his or her profession, to influence students in an educational way, and to develop their interests, abilities, talents, beliefs, and practical skills in every possible way, requires ownership[7].

To do this, constantly improve the professional skills, abilities and competencies of teachers, take care of them in all respects, create the necessary conditions, and provide the necessary material and scientificmethodological and technical assistance; creative work of teachers should be encouraged to increase its initiative on a regular basis.

On this basis, the subject "Pedagogical skills" serves to train skilled teachers, teaching the secrets of professional activity of teachers and educators, skills and providing information on its improvement. Learns the essence of pedagogical skills in teachers, ways, means, and forms of development of professional activity in the context of modern requirements[8].

Pedagogical skills teach teachers and educators pedagogical creativity, pedagogical techniques, interaction between teachers and students in the educational process, communication tactics, speech culture, thinking, spiritual and educational and organization and implementation of educational work, teaches the features of curbing behavior and emotions in the process, and provides information about the system of pedagogical activities that develop their profession. Pedagogical skills are developed on the basis of pedagogical activity of teachers.
Pedagogical activity is the work of specially trained teachers who are accountable to society and the state for preparing the younger generation for life and work. Prospective teachers should be aware of the following components of their teaching activities;

2. Socio-historical development of the teaching profession and the role of this profession in society[9].

In every society, as in previous systems, the most important task for teachers is to educate and educate young people who are the future of society. Even at the end of the primitive community system, youth educational institutions were established, where more experienced, experienced elders raised children. During the period of slavery, special schools were established for the children of slaves, and in ancient Greece, the person who taught children was called didaskal ("to teach", "teach"). The boys were led to school by one of the slaves, a slave educator ("paye") called a child, "agogayin" to lead. These concepts are still used today in relation to the teacher. But its essence takes on a different significance. In every society, educators are treated with great respect as educators and youth educators. Especially in our independent Uzbekistan, the respect and responsibility for teachers is growing[10].

Today, the number of creative teachers who make a significant contribution to improving the quality of teaching and educating the younger generation through their selfless work is growing every year. The competition for the best teachers is one of the reasons for this success. The number of Methodist teachers, senior teachers, Honored Teachers of Uzbekistan and People's Teachers of Uzbekistan is growing in schools[11]. 
3. On October 6, 1997, the Decree of the First President of the Republic of Uzbekistan "On radical reform of the system of education and training, upbringing of a harmoniously developed generation" was issued, which reads: In order to ensure the training of qualified teaching staff of higher education institutions, the study of their positive experience in the education of developed countries, to get acquainted with new pedagogical technologies and gain experience abroad, the Republic "Teacher" to establish a fund[12]. The fund was established to help train highly qualified teachers, to identify talented young teachers, to improve their professional skills, and to help them gain experience in advanced educational institutions and centers of developed democracies. In general, the training and retraining of teachers is in the focus of the state and the public; emphasis is placed on making teachers philosophically broadminded. The reason for this concern is that the future of our people, our nation, in many respects, depends on the teacher, his level and dedication. Pedagogical activity is the labor activity of specially trained people who are responsible to the people and the state for preparing the younger generation for life and work. The work of school teachers is aimed at shaping the human personality. Every child has his or her own personality. These features should be taken into account in education. It uses special methods that reflect the complexity of social relations between people. These are the qualities that young people preparing for teaching should know.

These characteristics of the teaching profession are reflected in the professiogram, which includes:

- $\quad$ Teacher's personality traits.
- Requirements for mental and pedagogical training of teachers.

- The scope and content of special training.

- The content of general training in the specialty.

- Teacher's personality traits: In the field of ideology: scientific worldview and faith, deep understanding of social needs and moral needs, understanding of social and civic duty, socio-political activism.

- In the field of pedagogical profession:

- love of children and interest in working with them,

- love of pedagogical work, mental pedagogical intelligence and observation,

- pedagogical delicacy,

- pedagogical imagination,

- organizational skills,

- honesty,

- kindness,

- perseverance and purposefulness,

- composure,

- Restraint professional competence.

Field of knowledge: wide scientific level, spiritual need and interest, intellectual interest, ability to feel new. Pedagogical activities enrich one's experience with the analysis and generalization of one's experiences.

\section{CONCLUSION}

The components of pedagogical skill that we have considered above mean that it is systematic. The obvious external features of pedagogical skills are: purposefulness of activity, composure, reasoning, thoroughness of students' knowledge, selection of the most appropriate means, creative approach to their work. An engineer-educator can achieve his / her skills in the following stages:

1. In-depth study of psychology and pedagogy; 
2. To have a thorough knowledge of special and general technical sciences, their teaching methods;

3. Active participation in pedagogical practice and its effective conduct;

4. Constantly analyze their activities, be critical of them, study the experience of others;

5. Independent work, training courses.

\section{REFERENCES}

1. History of Uzbek pedagogy. // Edited by A. Zunnunov. - T .: Teacher, 1997.-272 p.

2. 2.Criteria for evaluating and motivating the performance of the teacher (Methodical Recommendation). - T .: 1993. - 34 p.

3. Goziyev E. Psychology. - T .: o 'Andy, 1994. $-224 \mathrm{p}$.

4. Goziev E. Management of student learning. T .: o 'Andy, 1984. - 104 p.

5. Hasanboyev J., et al. Annotated dictionary of pedagogical sciences. T : Science and technology, 2009. - 672 p.

6. Harmoniously developed generation is the basis of development of Uzbekistan. T .: Sharq 1997-64 p.

7. N.P.Anikeeva. Spiritual environment in the community T .: "Teacher" 1993. 256 p.

8. Methods of educational work. // Handbook for pedagogical institutes (edited by L. I. Ruvinsky). - T .: Teacher, 1991. $-376 \mathrm{p}$.

9. There is no future without historical memory. // "Dialogue", 1998, issue 5.

10. Tolipov O., Usmonbaeva M. Pedagogical technology: theory and practice.- $\mathrm{T}$.: Science, 2005, - 206 p.

11. Turgunov S.T., Maqsudova L.A. Organization and management of pedagogical process. - T .: “Fan” 2009. $168 \mathrm{p}$.
12. Gaybullayev N.R., et al. Pedagogy: A Handbook for Higher Education Institutions. - T .: OczMU, 2005. - 176 p. 